\title{
Genótipos de milho para produção de minimilho em sistema de cultivo orgânico
}

\section{Corn genotypes for baby corn production in an organic cultural system}

\author{
Maxwel Rodrigues Nascimento ${ }^{1}$, Paulo Ricardo dos Santos ${ }^{2}$, Fábio Cunha Coelho $^{3}$, Kleyton Danilo da Silva Costa ${ }^{4}$, Tâmara \\ Rebecca Albuquerque de Oliveira ${ }^{5}$, Antônio Félix da Costa ${ }^{6}$
}

\begin{abstract}
Resumo: Minimilho é o nome dado à inflorescência feminina do milho antes da polinização, ou seja, é a espiga de milho em desenvolvimento colhida dois a três dias após a emissão dos estilos-estigmas. De textura fina, delicado e sabor adocicado, o minimilho tem se tornado um produto promissor para o mercado tanto interno quanto externo, sobretudo porque, no Brasil, o produto industrializado era, em sua maioria, importado da Tailândia. O objetivo com esse trabalho foi realizar análise produtiva de genótipos de milho para produção de minimilho em um sistema de cultivo orgânico. O experimento foi realizado no Instituto Federal do Espírito Santo campus Alegre, utilizando-se o delineamento em blocos casualizados com sete genótipos em quatro repetições. A variedade crioula Aliança e o híbrido duplo BM 207 apresentaram as maiores produtividades de espigas comerciais, com média de $2,92 \mathrm{t} \mathrm{ha}^{-1}$, e maior número de espigas comercias (365 495 espigas ha $^{-1}$ ). Apesar da variedade crioula Aliança não ter apresentado estande final de plantas dentro do intervalo ideal para produção de minimilho, esta obteve comportamento prolífico com um dos maiores números de espigas por planta $\left(3,35\right.$ espigas planta $\left.^{-1}\right)$ além de ter um dos maiores comprimentos de espigas comerciais $(8,10 \mathrm{~cm})$. Diante dos dados obtidos a variedade crioula Aliança é uma ótima opção para ser utilizada pelos pequenos produtores devido ao seu custo baixo de aquisição de sementes e, também, por apresentarem uma ampla adaptação em sistemas de baixo nível de investimento tecnológico além de manter a variabilidade genética nas condições naturais de cultivo.
\end{abstract}

Palavras-chave: Híbridos; Variedades; Zea mays L.

\begin{abstract}
Baby corn is the name given to the female inflorescence of maize before pollination, that is, it is the ear of corn in development harvested two to three days after the issuance of the styles-stigmas. With a fine, delicate texture and sweet taste, the baby corn has become a promising product for the domestic and foreign market, especially since in Brazil the processed product was mostly imported from Thailand. The objective of this work was to perform productive analysis of maize genotypes for the production of baby corn in organic production system. The experiment was conducted at the Alegre campus of the IFES, with a randomized block design with seven genotypes in four replicates. The Alliance creole variety and the double hybrid BM 207 presented the highest yields of commercial ears, with an average of $2.92 \mathrm{t} \mathrm{ha}^{-1}$, and a higher number of commercial ears $\left(365,495\right.$ ears $\left.^{-1} \mathrm{a}^{-1}\right)$. Although the creole Alliance variety did not present a final stand of plants within the ideal range for corn production, it had a prolific behavior with one of the highest number of ears per plant $\left(3.35\right.$ ears plant $\left.{ }^{-1}\right)$ and besides the largest lengths of commercial ears $(8.10 \mathrm{~cm})$. In view of the data obtained, the creole Alliance variety is a great option to be used by small producers due to their low cost of seed acquisition and also because they have a wide adaptation in systems of low level of technological investment besides maintaining the genetic variability in the natural conditions of cultivation.
\end{abstract}

Key words: Hybrids; Varieties; Zea mays L.

\footnotetext{
*Autor para correspondência

Recebido para publicação em 25/11/2017; aprovado em 20/05/2018

${ }^{1}$ Doutorando em Genética e Melhoramento de Plantas, Universidade Estadual do Norte Fluminense Darcy Ribeiro, maxwel.rn88@ gmail.com;

${ }^{2}$ Pós-Doutorando em Genética e Melhoramento de Plantas, Universidade Estadual do Norte Fluminense Darcy Ribeiro, prs_ufal@hotmail.com;

${ }^{3}$ Professor e Doutor na Universidade Estadual do Norte Fluminense Darcy Ribeiro, fabiocoelhouenf@gmail.com;

${ }^{4}$ Professor e Doutor no Instituto Federal de Educação, Ciência e Tecnologia de Alagoas, Campus Piranha, kd.agro@gmail.com;

${ }^{5}$ Doutoranda em Genética e Melhoramento de Plantas, Universidade Estadual do Norte Fluminense Darcy Ribeiro, tâmara_rebecca@hotmail.com;

${ }^{6}$ Doutor no Instituto Agronômico de Pernambuco, afelixc.ipa@gmail.com
} 


\section{INTRODUÇÃO}

Minimilho é o nome dado à inflorescência feminina do milho (Zea mays L.), antes da polinização, ou seja, é a espiga de milho em desenvolvimento, a qual se usa como alimento. Assim, o minimilho é produzido por meio de sementes de cultivares de milhos comerciais, semeadas em densidade elevada e colhidas dois a três dias após a emissão dos estilosestigmas. Ele é consumido in natura ou em conservas acidificadas na forma de petisco, picles, saladas e na confecção de pratos como risotos, sopas e guarnições acompanhadas com carnes e peixe grelhados (DO VALE et al.,2011).

O minimilho é um produto promissor para o mercado tanto interno quanto externo, sobretudo porque, no Brasil, o produto industrializado era, em sua maioria, importado da Tailândia. A crescente oferta deste produto nas gôndolas dos principais supermercados do país mostra o potencial do mercado consumidor brasileiro, possibilitando também a exportação principalmente para os Estados Unidos e União Europeia (DO VALE et al.,2011).O cultivo do minimilho pode ser comparado ao das hortaliças, pelo fato do período da semeadura até a colheita ser relativamente curto, em média 60 dias. Também, pelos cuidados que exige, principalmente na pós-colheita, quando as espigas devem ser acondicionadas em temperaturas que permitam sua conservação, entre 5 a $10^{\circ} \mathrm{C}$ (SANTOS et al., 2014). Esta hortaliça se adapta a vários sistemas de cultivo, onde merece destaque o orgânico.

A agricultura orgânica é definida como o sistema de manejo sustentável da unidade de produção rural, que privilegia a preservação ambiental, a agrobiodiversidade, os ciclos biológicos e a qualidade de vida do homem, visando à sustentabilidade social, ambiental e econômica (NEVES et al., 2004).

A agricultura familiar é constituída por pequenos e médios agricultores que são os maiores responsáveis pela produção de grande parte dos alimentos que abastecem a mesa dos brasileiros, como o feijão, arroz, milho, hortaliças, mandioca e pequenos animais. No entanto, grande parte dos agricultores familiares brasileiros,estão localizados em regiões onde é empregado um baixo nível tecnológico e áreas de plantio com problemas que dificultam adequado manejo fitotécnico das culturas agrícolas,onde nestas condições as cultivares de milho comerciais podem apresentar desempenho próximo ou mesmo inferior às variedades crioulas (CARPENTIERE-PÍPOLO et al., 2010).

As variedades crioulas, também conhecidas como raças locais ou landraces, são materiais importantes para o melhoramento vegetal, pelo elevado potencial de adaptação que apresentam para condições ambientais específicas (PATERNIANI et al., 2000). De maneira geral, as populações crioulas são menos produtivas que os cultivares comerciais, entretanto são importantes por constituírem fonte de variabilidade genética que podem ser exploradas na busca por genes tolerantes e/ou resistentes aos fatores bióticos e abióticos (ARAÚJO; NASS, 2002; CARPENTIERE-PÍPOLO et al., 2010). O Brasil apresenta condições edafoclimáticas favoráveis ao cultivo de milho para produção de minimilho, porém existem poucas informações a respeito do seu cultivo orgânico voltado para o agricultor familiar. Assim, objetivouse com este trabalho avaliar genótipos de milho para a produção de minimilho em sistema de cultivo orgânico.

\section{MATERIAL E MÉTODOS}

O experimento foi conduzido no ano de 2016 durante os meses de fevereiro a setembro, no setor de Horticultura do Instituto Federal de Educação, Ciência e Tecnologia do Espírito Santo, campus Alegre, situada entre as coordenadas $20^{\circ} 45^{\prime} 30^{\prime}$ latitude Sul e $41^{\circ} 27^{\prime} 23^{\prime \prime}$ longitude Oeste, com altitude de 108,27 m. O solo da área experimental apresentou as seguintes características químicas, na profundidade de 0 $20 \mathrm{~cm}: \mathrm{pH}=6,20 ; \mathrm{P}=79,70 \mathrm{mg} \mathrm{dm}{ }^{-3} ; \mathrm{K}^{+}=259 \mathrm{mg} \mathrm{dm}^{-3}$; $\mathrm{Ca}^{2+}=4,20 \mathrm{cmol}_{\mathrm{c}} \mathrm{dm}^{-3} ; \mathrm{Mg}^{+2}=1,20 \mathrm{cmol}_{\mathrm{c}} \mathrm{dm}^{-3} ; \mathrm{H}^{+}+\mathrm{Al}^{+3}=$ $2,80 \mathrm{cmol}_{\mathrm{c}} \mathrm{dm}^{-3}$; S.B. $=6,06 \mathrm{cmol}_{\mathrm{c}} \mathrm{dm}^{-3} ; \mathrm{CTC}=8,86 \mathrm{cmol}_{\mathrm{c}}$ $\mathrm{dm}^{-3} ; \mathrm{V} \%=68 ; \mathrm{S}=33 \mathrm{mg} \mathrm{dm}{ }^{-3} ; \mathrm{B}^{+3}=10,47 \mathrm{mg} \mathrm{dm}^{-3} ; \mathrm{Zn}^{2+}=$ $4,10 \mathrm{mg} \mathrm{dm}^{-3} ; \mathrm{Mn}=99 \mathrm{mg} \mathrm{dm}^{-3} ; \mathrm{Cu}=1,30 \mathrm{mg} \mathrm{dm}^{-3} ; \mathrm{Fe}=42$ $\mathrm{mg} \mathrm{dm}{ }^{-3} ;$ M.O. $=2,30 \mathrm{dag} \mathrm{m^{-3 }}$.

$\mathrm{O}$ delineamento experimental utilizado foi em blocos casualizados, com sete tratamentos constituídos por genótipos de milho, sendo quatro variedades (BR 106, Eldorado, Emcapa 201 e Capixaba Incaper 203), duas variedades crioulas procedentes do município de Muqui-ES (Aliança e Fortaleza) e um híbrido duplo precoce (BM 207). A variedade BR 106 é recomendada pela Embrapa Milho e Sorgo para plantio comercial de minimilho, portanto foi utilizada como testemunha. Os tratamentos foram avaliados em quatro repetições, totalizando um estande final de 28 parcelas experimentais. A unidade experimental consistiu de quatro fileiras de plantas de milho com 6,0 m de comprimento, espaçadas em 0,8 m entre linhas, no total de 19,2 $\mathrm{m}^{2}$. Durante avaliação do experimento foi utilizado as duas linhas centrais, descartando-se $0,5 \mathrm{~m}$ de cada extremidade, formando uma área útil de $8 \mathrm{~m}^{2}(5,0 \times 1,6 \mathrm{~m})$.

O experimento foi realizado em duas etapas, a primeira foi constituída pelo plantio de plantas de cobertura, crotalária (Crotalaria juncea L.), como pré-cultivo para formação da palhada, na segunda foi realizado o cultivo do milho para obtenção do minimilho. O preparo do solo foi realizado por meio de uma operação de aração e duas de gradagens leves. Um dia após esse procedimento a crotalária foi semeada a uma profundidade de $2 \mathrm{~cm}$, sendo esta feita manualmente, na densidade de 20 sementes por metro linear em fileiras duplas espaçadas de aproximadamente $4,0 \mathrm{~cm}$ e $0,5 \mathrm{~m}$ entre fileiras duplas, constituindo uma densidade de 800.000 plantas ha $^{-1}$, seguindo recomendações de Oliveira et al.(2004).

Aos 73 dias após a semeadura (DAS), quando a crotalária estava com mais $50 \%$ das plantas floridas foi feito ocorte por meio da roçadeira mecânica. A biomassa da crotalária foi deixada sobre o solo durante duas semanas. Transcorrido esse tempo, foi realizado a incorporação da biomassa que estava sobre o solo e a adubação de plantio com cama aviária na quantidade de $6 \mathrm{t} \mathrm{ha}^{-1}$, por meio da operação de gradagem (PEREIRA JÚNIOR et al., 2012). No dia seguinte foi realizada, manualmente, a abertura dos sulcos para o semeio do milho.

A cama aviária apresentou as seguintes características químicas: $\mathrm{N}=21,0 \mathrm{~g} \mathrm{~kg}^{-1} ; \mathrm{P}=8,80 \mathrm{~g} \mathrm{~kg}^{-1} ; \mathrm{K}=14 \mathrm{~g} \mathrm{~kg}^{-1} ; \mathrm{Ca}^{2+}=$ $116,60 \mathrm{~g} \mathrm{~kg}^{-1} ; \mathrm{Mg}^{2+}=6,70 \mathrm{~g} \mathrm{~kg}^{-1} ; \mathrm{S}=4,30 \mathrm{~g} \mathrm{~kg}^{-1} ; \mathrm{B}^{3+}=18,61$ $\mathrm{mg} \mathrm{kg}{ }^{-1} ; \mathrm{Zn}^{2+}=213,35 \mathrm{mg} \mathrm{kg}^{-1} ; \mathrm{Mn}=366,50 \mathrm{mg} \mathrm{kg} ; \mathrm{Fe}=725$ $\mathrm{mg} \mathrm{kg}^{-1} ; \mathrm{Cu}=69,05 \mathrm{mg} \mathrm{kg}^{-1}$.

$\mathrm{Na}$ segunda etapa do experimento as sementes de milho foram distribuídas uniformemente em sulcos na proporção de 33 sementes $\mathrm{m}^{-1}$. Aos 21 DAS, foi realizado o desbaste para se atingir uma população de 17 plantas $\mathrm{m}^{-1}$ de sulco, constituindo uma densidade de 212.500 plantas ha ${ }^{-1}$. 
O controle de plantas espontâneas foi realizado por meio de duas capinas manuais aos 20 e 40 DAS. Para o controle da lagarta-do-cartucho (Spodoptera frugiperda) foi realizada apenas uma pulverização aos 50 DAS com bactericida biológico a base de Bacillus thuringiensis. A quantidade utilizada foi de $500 \mathrm{~g} \mathrm{ha}^{-1}$ e a aplicação foi por meio de um pulverizador costal com capacidade de 20 litros.

A primeira colheita do minimilho foi realizada três dias após a emissão dos estilos-estigmas, aos 68 DAS. Após a colheita as espigas foram acondicionadas em câmara fria a temperaturas que oscilaram entre 5 e $12^{\circ} \mathrm{C}$ até o momento das determinações. A partir desse dia foram realizadas duas colheitas por semana no total de onze.

As variáveis obtidas para minimilho foram: número total de espigas (NTE), determinado através da contagem de todas as espigas da área útil da parcela e posteriormente feito o cálculo para números de espigas por hectare; massa total de espigas com palha e sem palha (MTE e MESP), pesadas em balança digital, as espigas com e sem a palha da área útil e depois feita a relação para produtividade em $\mathrm{t} \mathrm{ha}^{-1}$; massa de espigas comerciais e não comerciais (MEC e MENC), pesadas em balança digital, as espigas sem a palha comerciais e não comerciais da área útil e depois feita a relação para produtividade em $\mathrm{t} \mathrm{ha}^{-1}$; número de espigas comerciais (NEC) e não comerciais (NENC),determinadas através da contagem de todas as espigas comerciais e não comerciais da área útil da parcela e posteriormente feito o cálculo para números de espigas por hectare; rendimento de espigas comerciais (REND), porcentagem da relação MEC com MTE; diâmetro das espigas comerciais (DEC), medido em milímetros com um paquímetro digital no centro de cada espiga; comprimento das espigas comerciais (CEC), medido em centímetros com régua, da base ao ápice das espigas comerciais; diâmetro do colmo (DCP), medido em milímetros com um paquímetro digital, próximo ao coleto; altura da planta (ALT), medido em centímetros com fita métrica, da base do colmo até o ápice do pendão; estande final (EST), determinado através da contagem de plantas de milho da área útil e posteriormente feito o cálculo para hectare; número de espigas por planta (NEP), determinado através da relação do NTE com EST e massa da matéria seca da parte aérea da planta (MS), pesadas em balança digital, a matéria seca de três plantas de cada parcela e depois feita a relação para produtividade em $\mathrm{t} \mathrm{ha}^{-1}$.

Foram realizadas as análises de variância e o teste de Tukey a 5\% de probabilidade para a comparação das médias dos genótipos de milho para produção de minimilho, utilizando o software estatístico SISVAR 5.6 (FERREIRA, 2011).

\section{RESULTADOS E DISCUSSÃO}

A fonte de variação genótipos de milho para produção de minimilho, apresentou diferença significativa a 1 e $5 \%$ de probabilidade pelo teste $\mathrm{F}$ para todas as variáveis, exceto DEC (Tabela 1). Os coeficientes de variação apresentaram ótima precisão experimental para as variáveis REND, CEC, DEC, DCP e ALT (respectivamente, 9,36; 5,21; 2,50; 10,53 e $8,44)$; boa precisão experimental para MESP, MEC, NTE, NEC e EST (respectivamente, 19,72; 15,92; 16,71; 17,16 e 20,30); regular precisão experimental para MTE, NENC e NEP $(23,65 ; 24,63$ e 29,29 respectivamente); e baixa para MENC (39,50) (FERREIRA, 2000).

A variedade crioula Aliança e o híbrido BM 207 apresentaram os maiores valores de MTE, em média 15,42 t $\mathrm{ha}^{-1}$, em relação à variedade Emcapa $201\left(7,64 \mathrm{t} \mathrm{ha}^{-1}\right)$ (Tabela 1). As cultivares Aliança e BM 207 destacaram-se em relação MTE devido o fato de ter apresentado um dos maiores valores de NTE, em média, 403646 espigas ha ${ }^{-1}$ e EST, em média, 157292 plantas $\mathrm{ha}^{-1}$, que influenciam diretamente na produtividade de espigas (Tabela 2). Uma das possíveis causas que resultou na baixa produtividade da variedade Emcapa 201 foi ter apresentado um dos menores NTE (196 344 espigas $\mathrm{ha}^{-1}$ ) e EST (77 255 plantas $\mathrm{ha}^{-1}$ ), que correspondeu, em ambas as variáveis, a $49 \%$ das médias obtidas pelas duas cultivares (Tabela 2).

As variedades BR 106, crioula Aliança e o híbrido BM 207 apresentaram, em média, os maiores valores de MESP $\left(3,56 \mathrm{t} \mathrm{ha}^{-1}\right)$ em relação à variedade Emcapa $201\left(1,76 \mathrm{t} \mathrm{ha}^{-1}\right)$. No entanto a variedade Eldorado $\left(2,95 \mathrm{t} \mathrm{ha}^{-1}\right.$ não diferiu em relação a todos os cultivares (Tabela 1).

O híbrido BM 207 obteve maior MEC $\left(3,04 \mathrm{t} \mathrm{ha}^{-1}\right)$ que superou em $143 \%$ a produtividade obtida pela variedade Emcapa 201(1,25 $\left.\mathrm{t} \mathrm{ha}^{-1}\right)$ (Tabela 1). No entanto, as variedades BR 106 e crioula Aliança não diferiram do híbrido, apresentando em média $2,65 \mathrm{t} \mathrm{ha}^{-1}$ (Tabela 1). O número total de espigas comerciais e o estande final de plantas refletem significativamente na produtividade de espigas comerciais e partindo desse pressuposto a variedade Emcapa 201 apresentou uma das menores MEC devido o fato de ter um dos menores NEC (166 302 espigas ha $^{-1}$ ) e EST (77 255 plantas ha ${ }^{-1}$ ) (Tabela 2).

Tabela 1. Valores médios de caracteres produtivos de genótipos de milho para produção de minimilho. Alegre, Espírito Santo.

\begin{tabular}{lccccccc}
\hline Genótipos & MTE & MESP & MEC & MENC & REND & CEC & DEC \\
\hline Incaper 203 & $10,49 \mathrm{ab}$ & $2,64 \mathrm{bc}$ & $1,90 \mathrm{~cd}$ & $0,74 \mathrm{ab}$ & $18,16 \mathrm{ab}$ & $7,30 \mathrm{bc}$ & $13,48 \mathrm{a}$ \\
BR 106 & $11,80 \mathrm{ab}$ & $3,12 \mathrm{ab}$ & $2,50 \mathrm{abc}$ & $0,63 \mathrm{ab}$ & $21,14 \mathrm{a}$ & $7,26 \mathrm{bc}$ & $13,44 \mathrm{a}$ \\
Eldorado & $11,12 \mathrm{ab}$ & $2,95 \mathrm{abc}$ & $2,19 \mathrm{bc}$ & $0,76 \mathrm{ab}$ & $19,89 \mathrm{ab}$ & $7,81 \mathrm{abc}$ & $13,2 \mathrm{a}$ \\
Aliança & $16,54 \mathrm{a}$ & $4,07 \mathrm{a}$ & $2,80 \mathrm{ab}$ & $1,27 \mathrm{a}$ & $17,56 \mathrm{ab}$ & $8,10 \mathrm{ab}$ & $13,7 \mathrm{a}$ \\
Fortaleza & $11,26 \mathrm{ab}$ & $2,57 \mathrm{bc}$ & $1,84 \mathrm{~cd}$ & $0,74 \mathrm{ab}$ & $17,74 \mathrm{ab}$ & $8,40 \mathrm{a}$ & $13,04 \mathrm{a}$ \\
BM 207 & $14,30 \mathrm{a}$ & $3,49 \mathrm{ab}$ & $3,04 \mathrm{a}$ & $0,44 \mathrm{~b}$ & $21,37 \mathrm{a}$ & $7,28 \mathrm{bc}$ & $13,56 \mathrm{a}$ \\
Emcapa 201 & $7,64 \mathrm{~b}$ & $1,76 \mathrm{c}$ & $1,25 \mathrm{~d}$ & $0,51 \mathrm{~b}$ & $16,32 \mathrm{~b}$ & $6,99 \mathrm{c}$ & $13,37 \mathrm{a}$ \\
\hline Média & 11,88 & 2,94 & 2,22 & 0,73 & 18,89 & 7,59 & 13,40 \\
\hline CV \% & 23,65 & 19,72 & 15,92 & 39,50 & 9,36 & 5,21 & 2,50 \\
\hline
\end{tabular}

Médias seguidas pela mesma letra nas colunas não diferem estatisticamente entre si pelo teste de Tukey a 5\% de probabilidade; MTE $=$ massa total de espigas $\left(\mathrm{t} \mathrm{ha}^{-1}\right)$; MESP $=$ massa de espigas sem a palha $\left(\mathrm{t} \mathrm{ha}^{-1}\right) ; \mathrm{MEC}=$ massa de espigas comerciais $\left(\mathrm{t}\right.$ ha $\left.{ }^{-1}\right)$; MENC $=$ massa de espigas não comerciais $\left(\mathrm{t}\right.$ ha $\left.{ }^{-1}\right) ; \mathrm{REND}=$ rendimento de espigas comerciais $(\%) ; \mathrm{CEC}=$ comprimento de espiga comercial $(\mathrm{cm}) ; \mathrm{DEC}=$ diâmetro de espiga comercial $(\mathrm{mm})$. 
A produtividade de minimilho comercial (MEC) da variedade Eldorado (2,19 $\left.\mathrm{t} \mathrm{ha}^{-1}\right)$ superou em $174 \%$ a obtida por Corrêa et al. (2014) que avaliaram o rendimento dessa variedade em monocultivo e cultivo consorciado com a crotalária (Crotalaria juncea L.) antecedendo o cultivo da couve-folha no município de Seropédica-RJ. Da mesma forma, Silva et al. (2013) avaliaram o rendimento do híbrido duplo AG 1051 submetido à diferentes níveis de adubação nitrogenada para produção de minimilho, milho verde e milho grão no município de Mossoró-RN. A produtividade de minimilho comercial do tratamento submetido a $160 \mathrm{~kg} \mathrm{ha}^{-1}$ de $\mathrm{N}$ apresentou o maior valor, 2,51 $\mathrm{t} \mathrm{ha}^{-1}$, semelhante, portanto, à média obtida pela variedade BR $106\left(2,50 \mathrm{t} \mathrm{ha}^{-1}\right)$. Similarmente, Santos Neto (2012) avaliaram o potencial produtivo de dois genótipos de milho submetidos a diferentes lâminas de irrigação para produção de minimilho no município de Vitória da Conquista-BA e obteve do híbrido simples Itapuã 700 a maior produção de minimilho comercial $\left(3,15 \mathrm{t} \mathrm{ha}^{-1}\right)$, semelhante a média do híbrido duplo BM 207 $\left(3,04 \mathrm{t} \mathrm{ha}^{-1}\right)$. Os mesmos autores obtiveram média de massa total de espigas (MTE) de 11,33 $\mathrm{t} \mathrm{ha}^{-1}$ semelhante à média obtida neste estudo $\left(11,88 \mathrm{t} \mathrm{ha}^{-1}\right)$.

De forma semelhante, Lana et al. (2011) avaliaram o rendimento de quatro cultivares de milho (BRS Ângela, Eldorado, Super Doce e Doce Cristal) para produção de minimilho e fitomassa para adubação verde em um sistema orgânico de cultivo no município de Seropédica-RJ. A produção de minimilho comercial variou de 739 a $861 \mathrm{~kg} \mathrm{ha}^{-1}$ das cultivares Eldorado e Super Doce, respectivamente. A produtividade da variedade Eldorado obtida por Lana et al (2011) corresponde a 34\% da obtida pela mesma variedade neste trabalho. Jesus (2014) avaliou o desempenho de dois genótipos de milho (Super Doce tipo Havaí e Pipoca UENF 14) em consórcio com diferentes plantas da Família Fabaceae para produção de minimilho no município de Campos dos Goytacazes-RJ. A variedade Emcapa 201 (1,25 t ha $\left.{ }^{-1}\right)$, que obteve a menor média entre os tratamentos (Tabela 1), produziu cerca de 2,5 vezes mais minimilho do que a variedade de milho Pipoca UENF-14 (0,48 $\left.\mathrm{t} \mathrm{ha}^{-1}\right)$. A variedade crioula Aliança apresentou maior MENC (1,27 tha ${ }^{1}$ ) em relação ao híbrido BM 207 e a variedade Emcapa 201, que apresentaram, em média, 0,48 $\mathrm{t} \mathrm{ha}^{-1}$. A massa de espigas não comerciais (MENC) é uma variável que influencia no rendimento e na produtividade dos genótipos de milho. Quanto menor MENC maior será a MEC e, consequentemente, maior será a produtividade e mais rentável será o genótipo. Destaca-se nesta característica o híbrido BM $207\left(0,44 \mathrm{t} \mathrm{ha}^{-1}\right)$ cuja produção correspondeu a $35 \%$ da produção da variedade crioula Aliança $\left(1,27 \mathrm{t} \mathrm{ha}^{-1}\right)$ (Tabela 1). Isso ocorreu devido ao desenvolvimento precoce das espigas da variedade crioula Aliança em relação aos demais cultivares. A Emcapa 201 apresentou $0,51 \mathrm{t} \mathrm{ha}^{-1}$, enquanto que a BM 207 obteve $0,44 \mathrm{t} \mathrm{ha}^{-1}$ de MENC, porém se relacionar essa variável com MESP ter-se-ão 29 e $13 \%$ de massa de espigas não comercias em relação à massa total de espigas despalhadas, respectivamente. Nessa lógica o BM 207 é mais rentável. A variedade BR 106 e o híbrido BM 207 apresentaram, em média, os maiores valores REND (21\%) em relação à variedade Emcapa 201 (16\%) (Tabela 1). O rendimento de espigas comerciais (REND) é a porcentagem da relação da MEC com MTE. O colmo, as folhas, as palhas e os estilos-estigmas e espigas fora do padrão comercial das plantas para produção de minimilho podem ser utilizados para a alimentação animal, por serem ricos em nutrientes, especialmente proteínas, que podem variar de 6 a 14\%. Isso permite que os produtores de minimilho possam ter uma renda adicional na comercialização desses produtos (LEKAGUL et al., 1981). Quanto menor o rendimento das cultivares maior será a produção de palhas e dos estilosestigmas descartados. Em média o experimento produziu 9,61 $\mathrm{t} \mathrm{ha}^{-1}$ de matéria fresca constituída apenas de palhas, estilosestigmas e espigas fora do padrão comercial.

A variedade crioula Fortaleza obteve maior CEC que, em média, foi $1,19 \mathrm{~cm}$ maior que as espigas das variedades Capixaba Incaper 203, BR 106, Emcapa 201 e do híbrido BM 207. No entanto, a variedade Eldorado não diferiu em relação a todos os cultivares apresentando $7,81 \mathrm{~cm}$ (Tabela 1). No caso da Fortaleza foi observado em campo o desenvolvimento precoce das espigas logo após a emissão dos estilos-estigmas que apesar de não diferirem tanto em relação aos demais cultivares, as espigas com maior comprimento atraem mais os consumidores e também as indústrias de conservas que além dessa característica prezam também por espigas com maior uniformidade de ovários, coloração de branco pérola a amarelo creme, formato cilíndrico, comprimento de espigas de 40 a $120 \mathrm{~mm}$ e diâmetro de 10 a $18 \mathrm{~mm}$ (PEREIRA FILHO; CRUZ, 2001). Em relação ao DEC não foi observada diferença significativa entre as cultivares.

O CEC do experimento de Corrêa et al. (2014) foi em média $6,58 \mathrm{~cm}$, semelhante à média obtida pela variedade Emcapa $201(6,99 \mathrm{~cm})$, porém abaixo da média obtida pela mesma cultivar do experimento $(7,81 \mathrm{~cm})$ (Tabela 1). Em relação ao DEC a média dos tratamentos obtida pelos mesmos autores $(11,70 \mathrm{~mm})$ está abaixo da média obtida pelo experimento $(13,40 \mathrm{~mm})$. Moreira et al. (2014) avaliaram cinco genótipos de milho para produção de minimilho no município de Campo Mourão-PR e observaram que não houve diferença significativa em relação ao CEC que variou de 9,16 a 10,38 cm das cultivares de milho híbrido simples modificado ATL 200 e milho canjica AL Branco, respectivamente. Esses valores superam a média obtida pela variedade crioula Fortaleza $(8,40 \mathrm{~cm})$ (Tabela 1$)$.

O híbrido BM 207 apresentou maior NTE (419 792 espigas ha $^{-1}$ ) em relação às variedades Emcapa 201, crioula Fortaleza e Capixaba Incaper 203, que apresentaram em média 238451 espigas ha ${ }^{-1}$. No entanto, a variedade Eldorado não diferiu em relação a todos as cultivares, que apresentou 310677 espigas ha $^{-1}$ (Tabela 2). O híbrido BM 207 destacouse em relação ao NTE por ter apresentado um dos maiores MTE (14,30 $\mathrm{t} \mathrm{ha}^{-1}$ ) e EST (173 958 plantas ha ${ }^{-1}$ ), enquanto que a variedade Emcapa 201 apresentou os menores valores $\left(7,64 \mathrm{t} \mathrm{ha}^{-1}\right.$ e 77255 plantas ha ${ }^{-1}$ de MTE e EST, respectivamente) (Tabelas 1 e 2).

O híbrido BM 207 apresentou maior NEC (397 135 espigas ha $^{-1}$ ) em relação às variedades Emcapa 201, crioula Fortaleza, Eldorado e Capixaba Incaper 203 que apresentaram em média 224844 espigas ha $^{-1}$. Porém, as cultivares crioula Aliança e BR 106 não diferiram em relação ao híbrido e apresentaram em média 329687 espigas ha ${ }^{-1}$. O híbrido BM 207 além de ter apresentado o maior NEC (Tabela 2) também apresentou maior MEC $\left(3,04 \mathrm{t} \mathrm{ha}^{-1}\right)$ em relação à variedade Emcapa $201\left(1,25 \mathrm{t} \mathrm{ha}^{-1}\right)$. 
Tabela 2. Valores médios de caracteres biométricos e produtivos de genótipos de milho para produção de minimilho. Alegre, Espírito Santo.

\begin{tabular}{lccccccc}
\hline Genótipos & NTE & NEC & NENC & NEP & EST & DCP & ALT \\
\hline Incaper 203 & $282031 \mathrm{bcd}$ & $247396 \mathrm{bc}$ & $34635 \mathrm{ab}$ & $1,65 \mathrm{~b}$ & $172135 \mathrm{a}$ & $17,15 \mathrm{ab}$ & $2,73 \mathrm{ab}$ \\
BR 106 & $354427 \mathrm{abc}$ & $325521 \mathrm{ab}$ & $28906 \mathrm{~b}$ & $1,91 \mathrm{ab}$ & $187500 \mathrm{a}$ & $16,73 \mathrm{~b}$ & $2,43 \mathrm{~b}$ \\
Eldorado & $310677 \mathrm{abcd}$ & $277344 \mathrm{bc}$ & $33073 \mathrm{~b}$ & $2,22 \mathrm{ab}$ & $142708 \mathrm{ab}$ & $19,51 \mathrm{ab}$ & $2,89 \mathrm{ab}$ \\
Aliança & $387500 \mathrm{ab}$ & $333854 \mathrm{ab}$ & $53646 \mathrm{a}$ & $3,35 \mathrm{a}$ & $140625 \mathrm{ab}$ & $18,31 \mathrm{ab}$ & $3,25 \mathrm{a}$ \\
Fortaleza & $236979 \mathrm{~cd}$ & $208333 \mathrm{c}$ & $28646 \mathrm{~b}$ & $2,51 \mathrm{ab}$ & $97135 \mathrm{c}$ & $21,34 \mathrm{a}$ & $3,21 \mathrm{a}$ \\
BM 207 & $419792 \mathrm{a}$ & $397135 \mathrm{a}$ & $22656 \mathrm{~b}$ & $2,43 \mathrm{ab}$ & $173958 \mathrm{a}$ & $18,23 \mathrm{ab}$ & $2,54 \mathrm{~b}$ \\
Emcapa 201 & $196344 \mathrm{~d}$ & $166302 \mathrm{c}$ & $30042 \mathrm{~b}$ & $2,59 \mathrm{ab}$ & $77255 \mathrm{c}$ & $18,72 \mathrm{ab}$ & $2,64 \mathrm{~b}$ \\
\hline Média & 312536 & 279412 & 33086 & 2,38 & 141617 & 18,57 & 2,81 \\
\hline CV \% & 16,71 & 17,16 & 24,63 & 29,29 & 20,30 & 10,53 & 8,44 \\
\hline
\end{tabular}

Médias seguidas pela mesma letra nas colunas não diferem estatisticamente entre si pelo teste de Tukey a 5\% de probabilidade; NTE= número de espigas por planta $\left(\right.$ espigas ha $\left.{ }^{-1}\right) ; \mathrm{NEC}=$ número de espigas comerciais $\left(\right.$ espigas ha $\left.{ }^{-1}\right) ; \mathrm{NENC}=$ número de espigas não comerciais $\left(\right.$ espigas ha $\left.{ }^{-1}\right) ; \mathrm{NEP}^{-1}$ número de espigas por planta (espigas planta $\left.{ }^{-1}\right)$; EST= estande final de plantas (plantas ha $\left.{ }^{-1}\right) ; \mathrm{DCP}=$ diâmetro do colmo da planta $(\mathrm{mm}) ; \mathrm{ALT}=$ altura da planta $(\mathrm{m})$.

Moreira et al. (2010) avaliaram o rendimento de dois híbridos duplos de milho na produção de minimilho sob o efeito do despendoamento no município de Mossoró-RN. Os maiores valores obtidos de NTE do híbrido BRS 2020 (254 203 espigas ha ${ }^{-1}$ ) e NEC do híbrido AG 1051 (228 725 espigas ha $^{-1}$ ) são muito inferiores aos obtidos pelo híbrido BM 207 (respectivamente, 419792 e 397135 espigas ha $^{-1}$ ) (Tabela 2).

$\mathrm{O}$ número de espigas não comerciais (NENC) é uma variável que influencia no número de espigas comerciais. Quanto menor for o número de espigas fora do padrão comercial, maior será o número de espigas comerciais. A variedade crioula Aliança apresentou o maior valor de NENC

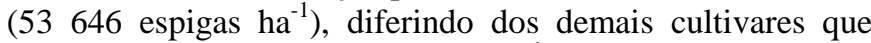

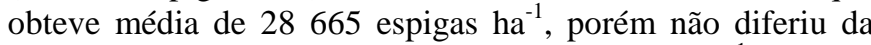
variedade Capixaba Incaper 203 (34 635 espigas ha $^{-1}$ ) (Tabela 2). Foi observado no campo que a cultivar crioula Aliança apresentou crescimento mais acelerado das espigas imaturas, em relação às demais cultivares. Certamente, um menor intervalo entre as colheitas poderá resultar em decréscimo das perdas para esta cultivar, em termos de NENC.

A variedade crioula Aliança apresentou maior NEP $\left(3,35\right.$ espigas planta $\left.^{-1}\right)$ em relação à variedade Capixaba Incaper $203\left(1,65\right.$ espigas planta $\left.^{-1}\right)$, enquanto que as demais cultivares apresentaram, em média, 2,33 espigas planta ${ }^{-1}$, porém não diferiram em relação à todas as cultivares (Tabela 2).

A cultura de minimilho pode proporcionar até quatro colheitas sucessivas, isso ocorre certamente por fatores fisiológicos ou a quebra da dominância apical, que estimula a brotação lateral e, consequentemente, a emissão de novas espigas, logo após a colheita da primeira, e assim sucessivamente, até quatro espigas por planta (CARVALHO et al., 2002). A variedade crioula Aliança apresentou maior comportamento prolífico e obteve o dobro de NEP em relação à variedade Emcapa 201, enquanto que a média dos demais tratamentos, que apresentaram valores intermediários, foi de $2,33 \mathrm{~cm}$ (Tabela 2).

O NEP obtido pela variedade Eldorado (2,22 espigas planta $^{-1}$ ) superou a $144 \%$ a média da mesma variedade consorciada com crotalária $\left(0,91\right.$ espigas planta $\left.^{-1}\right)$ avaliada por Corrêa et al. (2014).

Meneghetti et al. (2008) avaliaram o rendimento do milho pipoca BRS Ângela por evapotranspiração para produção de minimilho. Os autores observaram que a variável NEP foi maior $\left(3,13\right.$ espigas planta $\left.^{-1}\right)$ para o tratamento 30 mm de acúmulo baseado na evaporação do tanque classe $\mathrm{A}$, sendo, portanto semelhante ao obtido pela variedade crioula Aliança (3,35 espigas planta $^{-1}$ ) (Tabela 2). De acordo com esses autores, os melhores rendimentos têm sido obtidos com densidades populacionais entre 150.000 a 200.000 plantas ha ${ }^{1}$, objetivando maior produtividade e redução do tamanho do produto final, que é ideal para as indústrias de conservas. As variedades BR 106, Capixaba Incaper 203 e o híbrido BM 207 apresentaram, em média, 177864 plantas ha $^{-1}$, porém não diferiram das variedades Eldorado e crioula Aliança que obtiveram, em média, 141667 plantas ha $^{-1}$ (Tabela 2). No entanto as variedades Emcapa 201 e crioula Fortaleza apresentaram os menores estandes, que foi, em média, 87195 plantas $\mathrm{ha}^{-1}$, que corresponde a $58 \%$ do intervalo mínimo de densidades de plantas para a cultura do minimilho (Tabela 2).

A média do EST da variedade Eldorado (142 708 plantas $\mathrm{ha}^{-1}$ ) (Tabela 2), mesmo estando abaixo da densidade populacional recomendada, se assemelha à média obtida pelo milho pipoca UENF 14 do experimento de Jesus (2014). A variedade crioula Aliança, mesmo apresentando valor de EST abaixo do recomendado (140 625 plantas $\mathrm{ha}^{-1}$ ), obteve uma das maiores produções de minimilho comercial $\left(2,8 \mathrm{t} \mathrm{ha}^{-1}\right)$, isso devido ao maior NEP (3,35 espigas planta ${ }^{-1}$ ) (Tabela 2$)$.

Em relação à altura das plantas (ALT) as cultivares crioulas Aliança e Fortaleza apresentaram as maiores estaturas, em média, apresentaram 3,23 m, em relação às cultivares BM 207, BR 106 e Emcapa 201, que apresentaram, em média 2,54 m. No entanto as variedades Capixaba Incaper 203 e Eldorado não diferiram entre os cultivares (Tabela 2).

Plantas mais altas podem formar inflorescências em partes mais altas, dificultando a colheita que é feita manualmente. Plantas de menor estatura são mais fáceis de manejar além de facilitar a colheita devido à altura de inserção das espigas serem mais baixas. Além disto, plantas de milho mais altas são mais susceptíveis ao tombamento e acamamento, principalmente em regiões em que as incidências de ventos fortes são constantes. O tombamento das plantas foi visualmente maior nas plantas mais altas, entretanto, este dado não foi mensurado nesta pesquisa.

Plantas de menor estatura permitem a realização da prática do despendoamento, ou seja, da remoção do pendão ou inflorescência masculina com objetivo de estimular o desenvolvimento mais rápido e aumentar a produtividade de espigas. Isso ocorre devido à quebra da dominância apical, onde se localiza a inflorescência masculina, que é um grande consumidor de energia. Com a retirada do pendão, há um estímulo de brotações de gemas laterais, dando origem a novas inflorescências femininas, que poderão ser colhidas 
como minimilho, três a quatro dias após o despendoamento (AEKATASANAWAN, 2001). Além dos benefícios acima citados, o despendoamento evita a fertilização, uma vez que, com a polinização e o início da formação do grão, as espigas tornam-se inadequadas sob o ponto de vista comercial (AEKATASANAWAN, 2001).

Araújo et al. (2013) observaram que a variedade crioula "Argentino" demonstrou maior susceptibilidade ao acamamento por ter apresentado maior altura de planta. O mesmo foi observado nesse estudo, em que as cultivares crioulas Fortaleza e Aliança apresentaram maior susceptibilidade ao acamamento, devido ao menor número do estande final e maiores alturas de plantas (Tabela 2). A variedade Emcapa 201 apresentou o menor estande final de plantas (77 255 plantas $\mathrm{ha}^{-1}$ ), devido ao baixo potencial germinativo em virtude da idade das sementes que, na época que foram obtidas pelo Instituto Capixaba de Pesquisa Assistência Técnica e Extensão (INCAPER), tinha dois anos (Tabela 2).

Os resultados obtidos por Santos et al. (2014) para a altura de planta do milho de pipoca híbrido IAC 125 foram maiores na safra verão $(2,17 \mathrm{~m})$, porém inferior ao híbrido duplo BM 207 (2,53 m) (Tabela 2), no entanto em ambos a estatura da planta é ideal para o manejo da cultura de milho. As plantas de menor estatura são mais fáceis de colher devido à altura de inserção das espigas serem mais visíveis e acessíveis.

Em relação ao diâmetro do colmo da planta (DCP) houve diferença significativa, sendo que a variedade crioula Fortaleza $(21,34)$ apresentou o maior valor, superando em 28\% a variedade BR 106 (Tabela 2). A variedade BR 106 apresentou um dos menores DCP $(16,73 \mathrm{~mm})$, porém, obteve um dos maiores EST (187 500 plantas ha ${ }^{-1}$ ). Por outro lado, a variedade crioula Fortaleza obteve um dos maiores DCP (21,34 mm), no entanto obteve um dos menores EST (97 140 plantas $\left.\mathrm{ha}^{-1}\right)$. Araújo et al. (2013) avaliaram a influência de diferentes sistemas tecnológicos de manejo sobre os caracteres agronômicos de quatro genótipos de milho, sendo duas variedades crioulas ('Argentino' e o 'BR da Várzea') e dois híbridos (SHS 4080 e IAC 8333). O valor de DCP da variedade crioula 'Argentino', 21,42 mm, é semelhante ao obtido pela variedade crioula Fortaleza (Tabela 2), porém esses autores não observaram diferença significativa entre as cultivares. É possível concluir que devido o maior índice de tombamento e sementes não germinadas que resultaram em menor estande final de plantas, ou seja, quanto menor o número de plantas no sulco de cultivo menor será a competição por água, luz e nutrientes e maior será o acúmulo de matéria seca que resultará em maiores diâmetros do colmo.

\section{CONCLUSÃO}

As variedades BR106 e crioula Aliança e o híbrido BM207 são as com maior produção de espigas comercias de minimilho e maior número total e de espigas comercias. A variedade crioula Aliança, tem um dos maiores números de espigas por planta e um dos maiores pesos e número de espiga fora do padrão comercial e altura da planta.

A variedade crioula Aliança é uma ótima opção para os agricultores familiares, tendo um baixo custo de aquisição de sementes, e ampla adaptação em sistemas de baixo nível de investimento tecnológico além de manter a variabilidade genética nas condições naturais de cultivo.

\section{REFERÊNCIAS}

ARAÚJO, A. V.; BRANDÃO JÚNIOR, D. S.; FERREIRA, I. C. P. V.; COSTA, C. A.; PORTO, B. B. A. Desempenho agronômico de variedades crioulas e híbridos de milho cultivados em diferentes sistemas de manejo. Ciência Agronômica, Fortaleza, v.44, n.4, p.885-892, 2013. http://dx.doi.org/10.1590/S1806-66902013000400027.

ARAÚJO, P. M.; NASS, L. L. Caracterização e avaliação de populações de milho crioulo. Scientia Agricola, Piracicaba, $\begin{array}{llll}\text { v.59, n.3, } & \text { p.59: } & \text { 589-593, }\end{array}$ http://dx.doi.org/10.1590/S0103-90162002000300027.

CARPENTIERI-PÍPOLO, V.; SOUZA, A.; SILVA, D. A.; BARRETO, T. P.; GARBUGLIO, D. D.; FERREIRA, J. M. Avaliação de cultivares de milho crioulo em sistema de baixo nível tecnológico. Acta Scientiarum Agronomy, Maringá, v.32, n.2, p.229-233, 2010. http://dx.doi.org/10.4025/actasciagron.v32i2.430.

CARVALHO, G. S.; PINHO, R. G. V.; PEREIRA FILHO, I. A. Efeito do tipo de cultivar, despendoamento das plantas e da época de semeadura na produção de minimilho. Rev. Brasileira de Milho e Sorgo, Sete Lagoas, v.1, n.3, p.47-58, 2002.

CORRÊA, A. L.; ABBOUD, A. C. S.; GUERRA, J. G. M.; AGUIAR, L. A; RIBEIRO, R. L. Adubação verde com crotalária consorciada ao minimilho antecedendo a couvefolha sob manejo orgânico. Ceres, Viçosa, v.61, n.6, p.956963, 2014. http://dx.doi.org/10.1590/0034737X201461060010.

DO VALE, J. C.; FRITSCHE-NETO, R.; SILVA, P. S. L. Índice de seleção para cultivares de milho com dupla aptidão: minimilho e milho verde. Bragantia, Campinas, v.70, n.4, p.781-187, 2011. http://dx.doi.org/10.1590/S000687052011000400008 .

FERREIRA, D. F. Sisvar: a computer statistic alanalysis system. Ciência e Agrotecnologia, Lavras, v.35, n.6, p.10391042, 2011.

FERREIRA, P. V. Estatística experimental aplicada à Agronomia. $3^{\mathrm{a}}$ ed. Maceió: UFAL, 2000. 422p.

JESUS, V. P. Manejo orgânico de milho doce e pipoca, visando à produção de minimilho. Campos dos Goytacazesz: UENF, 2014. 67p.

LANA, L. O.; CORDEIRO, A. A. S.; GUERRA, J. G. M.; ESPÍNDOLA, J. A. A.; ARAÚJO, E. S. Avaliação de diferentes genótipos de milho com potencial para produção de minimilho e fitomassa para adubação verde. Cadernos de Agroecologia, Pelotas, v.6, n.2, 6 p., 2011.

LEKAGUL, T.; PERNMAMKHONG, S.; CHUTKAEW, C.; BENJASIL, V. Field corn variety for young ear corn production. National Cornand Sorghum Program Annual Report, v.13, p.201-205, 1981. 
MENEGHETTI, A. M.; SANTOS, R. F.; NÓBREGA, L. H. P.; MARTINS, G. I. Análise de crescimento de minimilho submetido a lâminas de irrigação. Acta Scientiarum Agronomy, Maringá, v.30, n.2, p.211-216, 2008. http://dx.doi.org/10.4025/actasciagron.v30i2.1730.

MOREIRA J. N.; SILVA P. S. L.; SILVA K. M. B.; DOMBROSKI J. L. D.; CASTRO R. S. Effect of detasseling on baby corn, green ear and grain yield of two maize hybrids. Horticultura Brasileira, Brasília, v.28, n.4, p.406-411, 2010. http://dx.doi.org/10.1590/S0102-05362010000400005.

MOREIRA, A.; SANTOS, M. Z.; FAVARÃO, S. C. M. Características agronômicas de genótipos de milho para produção de minimilho. Agronegócios e MeioAmbiente, Maringá,v.7, n.3, p.633-643, 2014.

NEVES, M. C. P.; ALMEIDA, D. L.; DE-POLLI, H.; GUERRA, J. G. M.; RIBEIRO, R. L. D. Agricultura orgânica - uma estratégia para o desenvolvimento de sistemas agrícolas sustentáveis. Seropédica: EDUR, 2004.98p.

OLIVEIRA F. L.; RIBEIRA R. L. D.; SILVA V. V.; GUERRA J. G. M.; ALMEIDA D. L. Desempenho do inhame (taro) em plantio direto e no consórcio com crotalária, sob manejo orgânico. Horticultura Brasileira, Brasília v.22, n.3, p.638-641, 2004. http://dx.doi.org/10.1590/S010205362004000300028 .

PATERNIANI, E.; NASS, L. L.;SANTOS, M. X. O valor dos recursos genéticos de milho para o Brasil: uma abordagem histórica da utilização do germoplasma. In: UDRY, CW; DUARTE, W. (Eds.). Uma história brasileira do milho: o valor dos recursos genéticos. Brasília: Paralelo 15, 2000.p.1114.

PEREIRA FILHO, I. A.; CRUZ, J. C. Manejo cultural de minimilho. Embrapa Milho e Sorgo: Sete Lagoas, 2001. 4p. (EMBRAPA - CNPMS. Circular Técnica, 7).

PEREIRA JÚNIOR E. B.; HAFLE O. M.; OLIVEIRA F. T.; OLIVEIRA F. H. T.; GOMES E. M. Produção e qualidade de milho-verde com diferentes fontes e doses de adubos orgânicos. Revista Verde de Agroecologia e Desenvolvimento Sustentável, Pombal, v.7, n.2, p.277-282, 2012.

SANTOS NETO, I. J. Cultivares de milho e lâminas de irrigação para produção de minimilho em Vitória da Conquista - BA. Vitória da Conquista: UESB, 2012. 67p.

SANTOS, R. F.; INOUE, T.T.; SCAPIM, C. A.; CLOVIS, L. R.; MOTERLE L.M.; SARAIVA, F. C. S. 2014. Produtividade do minimilho em função das adubações nitrogenadas e potássica. Ceres, Viçosa, v. 61, n.1, p.121-129, 2014. http://dx.doi.org/10.1590/S0034-737X2014000100016

SILVA P. S. L.; ARAÚJO JÚNIOR B. B.; OLIVEIRA V. R.; PONTES F. S. T.; OLIVEIRA O. F. Effects of nitrogen application on corn yield after harvesting the apical ear as baby corn. Horticultura Brasileira, Brasília v.31, n.3, p.419425, 2013. http://dx.doi.org/10.1590/S010205362013000300012 . 